\title{
Pt based Catalytic Coatings on Poly(benzimidazole) Micromonoliths for Indoor Quality \\ Control
}

\author{
A. Eguizabal ${ }^{1}$, M.A. Urbiztondo ${ }^{1,2}$, M.P. Pina ${ }^{1,3, *}$ \\ ${ }^{1}$ Nanosciencelnstitute of Aragón (INA); University of Zaragoza; Edif. I+D+i, Campus Rio Ebro, \\ c/Mariano Esquillor s/n, 50018 Zaragoza, Spain. \\ ${ }^{2}$ Centro Universitario de la Defensa, Academia General Militar, 50090 Zaragoza, Spain \\ ${ }^{3}$ Networking Research Center on Bioengineering, Biomaterials and Nanomedicine, CIBER-BBN, \\ 50018Zaragoza, Spain
}

Corresponding Author: tel. +34 976 761155, fax. +34 976762142

e-mail: $\underline{\text { mapina@unizar.es }}$

Abstract

Flexible Polybenzimidazole (PBI) micromonoliths prepared by microtransfer molding are herein proposed for the first time as G-S contactors for catalytic applications. Macroporous polymeric supports with 20 microns as characteristic length and $70000 \mathrm{~m}^{-1}$ as $\mathrm{S} / \mathrm{V}$ ratio have been coated by covalent linkage with Pt supported on amino functionalized ETS-10 crystals. As a proof of concept, the catalytic performance of the Pt modified PBI micromonoliths has been successfully demonstrated for indoor quality control, i.e. n-hexane removal at ppm level. 


\section{Keywords}

Macroporous Polybenzimidazole; straight pores; microtransfer molding; microstructured PBI reactor; supported Pt; titanosilicates; VOC removal; indoor quality

\section{Introduction}

Polybenzimidadole (PBI) has emerged as a well-known heterocyclic polymer due to its exceptional thermal stability (glass transition temperature above $400{ }^{\circ} \mathrm{C}$ ) and remarkable chemical resistance in both reductor and oxidant environments. It was commercially developed by Celanese Corporation as a fire-retardant material in 1983. Since Savinell's patent in 1996 [1], acid-base PBI membranes area among the mostly studied for high temperature proton exchange membrane fuel cells (PEMFCs) [2-3].

Among the numerous technological applications of $\mathrm{PBI}$, the coordinating ability of its benzimidazole group, make this polymer an excellent candidate as a metal catalyst support [47]. With the aim to improve the surface area to volume ratio and the number of exposed catalytic sites, PBI fibers with $262 \mathrm{~nm}$ in diameter and $7.5 \mathrm{~m}^{2} / \mathrm{g}$ as specific BET surface area, have been recently studied by Walmsley et. al [7] as oxovanadium (IV) support material. The mat like three-dimensional catalytic PBI structure was successfully tested in a continuous flow reactor for the catalytic oxidation of thioanisole. Until now, the reported heterogeneous catalytic tests with PBI microspheres [4-6] or electrospun nanofibers [7] have been performed at temperatures below $80^{\circ} \mathrm{C}$. However, its thermal stability allows applications under even more demanding conditions where most other polymer supports would fail.

Porous polymers have great potential in sensors, catalysis, drug delivery, membrane science or as optical or dielectric materials. These high value applications have motivated an intense research on reliable methods for the preparation of porous polymer architectures with specific pore geometry, pore size, pore surface and framework structure [8]. The direct 
template methodology simplifies notably the process since the template structure is fixed. It essentially involves sacrificial templates, not only solvent molecules, surfactants or polymers and their micelles and lyotropic phases, but also inorganic nanoparticles. Following this latter approach, mesoporous PBI with specific BET surface area above $180 \mathrm{~m}^{2} / \mathrm{g}$ has been synthesized by using a well defined $13 \mathrm{~nm}$ silica nanosol as hard template [9]. In our previous work [10], meso-macroporous PBI membranes were obtained by phase separation method and further deployed as ionic liquid containers for proton conduction at elevated temperatures under non-humidified conditions [10-11]. Unlike previously, direct synthesis methodology based on Suzuki cross-coupling reaction type has been recently proposed [12] to prepare porous PBI with $385 \mathrm{~m}^{2} / \mathrm{g}$ and promising carbon dioxide uptake properties $(8.0 \mathrm{wt} \%$ at 1.0 bar and $273 \mathrm{~K}$ ). The preparation of macroporous PBI by leaching out a low-molecularweight compound from polymer/porogen mixtures was firstly reported by Mecerreyes et al. in 2004 [13]. Based on this straightforward route, hybrid macroporous PBI membranes containing ETS-10 titanosilicate type materials functionalized with sulfonic groups have been attempted by our group to promote proton conduction keeping lower the phosphoric acid uptake values [14]. In a step further, cross-linked porous PBI with both outstanding mechanical properties and high proton conductivity have been prepared by Hsu et al [15].

Over the last decade, unconventional nanofabrication techniques, mainly molding, embossing and printing related techniques [16] have paved the way for $2 \mathrm{D}$ and $3 \mathrm{D}$ polymer structures with micrometer- and nanometer-sized features. The fully on-chip integration by simple operational procedures of such microstructured polymers will allow multiple unit operations in many areas where high resolution photolithography is unaffordable. Molding involves curing a precursor (usually a monomer or a prepolymer) against a topographically patterned substrate. This method of pattern transfer is used, among other techniques, by the microtransfer molding. Over the last decade, the phase separation micromolding technique has been extensively developed by Lammertink et al [17-20] to prepare a broad spectrum of 
polymeric microsieves (poly methyl methacrylate, polycarbonate, polystyrene, poly vinyl difluoride, polyimide, polylacticacid, polyaniline, etc...) with tunable porosity either with a hard mold [17-19] or a soft permeable elastomeric mold [20].

In this work, microtransfer molding technique has been used to prepare $\mathrm{PBI}$ micromonoliths from a relief pattern of poly (dimethylsiloxane) mold according to our previous work [21]. Accounting from the high thermal and chemical stability of PBI, the so obtained microstructured polymer supports have been employed as microreactors for the catalytic abatement of volatile organic compounds (n-hexane as model pollutant) up to $350^{\circ} \mathrm{C}$.

Microreaction engineering still has to face many remaining problems, and one of the most pressing relates to the development of methods to deposit a sufficient amount of catalyst in the microdevice. These coatings should not only provide enough catalytic loading, but be able do this in a homogeneous way, with high mechanical stability, low pressure-drop and good accessibility of the reactants to the catalyst (high external surface/volume ratio in the coating). Mostly, the solutions have generally aimed towards the deposition of thin catalytic coatings on the reactor wall [22]. Given the unique properties of microporous zeolites and related materials, significant efforts have been carried out in our group to combine the experience gathered in growing zeolites and the fabrication methods used in the IC industry to prepare microstructured supports with new functionalities [23-25]. In particular, Si substrates providing external area for the zeolite films around $300000-750000 \mathrm{~m}^{2} / \mathrm{m}^{3}$ of reactor volume have been tested for VOC catalytic removal due to mass transfer limitations are controlling the reaction rate [26-27]. In our recent work [27], regular structures of $\mathrm{SiO}_{2}$ micro monoliths with a diameter of 3-5 microns, created on silicon wafers, were covered with a uniform MFI type film after only $4 \mathrm{~min}$ of hydrothermal synthesis at $453 \mathrm{~K}$ assisted by microwave heating. The thin Pt-ZSM5 zeolite coating ( $<1$ micron) provided a short diffusion path length, underlying the potential of these microstructures as highly efficient contactors. The registered light of temperature for the catalytic combustion of $200 \mathrm{ppmV}$ of $\mathrm{n}$-hexane in air was $215^{\circ} \mathrm{C}$ for $34 \mathrm{~ms}$ 
as contact time. In this work, such $\mathrm{SiO}_{2}$ micromonoliths have been replaced by a $\mathrm{PBI}$ micromonolith-type stack comprising PBI microsieves with a channel diameter of 20 microns. The motivation of the flexible PBI micromonolith concept is to reduce costs, simplify the manufacturing process and improve the robustness of the whole reaction device.

The first part of this work is devoted to the preparation and characterization of different Pt based catalysts on zeolite type microporous supports. Special attention has been paid to the surface functionalization of the microporous crystals and the Pt anchoring strategies. As a conclusion, the catalyst exhibiting the lowest light-off temperature for $n$-hexane is identified. In the second part, the preparation and characterization of PBI micromonolith type stack activated with the outstanding catalyst is studied. Thanks to the reactivity of the benzimidazole ligand, the selected catalyst has been anchored on the polymer surface by covalent linkage. Finally, the performance of the catalytic films on the PBI micromonolith channels is demonstrated for hexane removal at ppm level.

\section{Experimental}

\section{Zeolite and Zeotype Synthesis}

ETS-10 titanosilicate type microporous material, $500 \mathrm{~nm}$ in particle size, was synthesized following the procedure already described in our previous work [14]. Similarly, colloidal NaYtype zeolite was hydrothermally synthesized from a gel with the following molar composition $0.04 \mathrm{Na}_{2} \mathrm{O} / 2.46(\mathrm{TMA})_{2} \mathrm{O} / 1 \mathrm{Al}_{2} \mathrm{O}_{3} / 3.4 \mathrm{SiO}_{2} / 370 \mathrm{H}_{2} \mathrm{O}$. The reactants used were Ludox AS40, aluminium isopropoxide ( $>98 \%$ Aldrich), tetramethylammonium hydroxide (TMAOH, $97 \%$ Sigma) and sodium hydroxide $0.1 \mathrm{M}$ solution ( $\mathrm{NaOH}, 97 \%$, Sigma-Aldrich). Firstly, a solution containing DDW, $\mathrm{NaOH}$ and $\mathrm{TMAOH}$ was prepared. After complete mixing, the Al precursor was added followed by the Si source and kept under vigorous stirring. The resulting solution was transferred to a three-neck round bottom flask adaptable in the rotary evaporator. The 
hydrothermal synthesis took place at $100{ }^{\circ} \mathrm{C}$ and $80 \mathrm{rpm}$ for more than $12 \mathrm{~h}$, until a white transparent colour in the solution was observed. The resulting colloidal suspension was thoroughly washed with DDW by centrifugation using 15 minutes cycles at $10000 \mathrm{rpm}$ until pH below 10. Afterwards, the recovered product was dried at $100^{\circ} \mathrm{C}$ and calcined in air flow at $420^{\circ} \mathrm{C}$ with a heating rate of $0.5^{\circ} \mathrm{C} / \mathrm{min}$ for $8 \mathrm{~h}$ to remove the structure-directing agent (TMAOH) from the zeolite pores.

\section{Aminosilanes Grafting}

Both ETS-10 and NaY microporous materials were functionalized with amine groups by grafting method using organosilanes as coupling agents. Mainly, two different procedures were studied to analyse the effect of amine groups density (N/Si ratio from 1 to 5 ) and molecular structure (linear or ramified) on Pt loading and dispersion.

Firstly, the synthesized materials were functionalized with commercial (3Aminopropyl)triethoxisilane (Aldrich, $98.0 \% \mathrm{wt}$ ), denoted as APTES for the remainder of this work, according to the following procedure. After drying at $200{ }^{\circ} \mathrm{C}$ during $3 \mathrm{~h}$, thus keeping free $-\mathrm{OH}$ groups on the surface, $1 \mathrm{~g}$ of the microporous material was introduced in a threeneck round bottom flask and evacuated for 20 minutes. Under Ar atmosphere, $150 \mathrm{~mL}$ of anhydrous toluene (Aldrich, $99.8 \%$ wt.) were added and the resulting suspension was kept under sonication for 15 minutes. Afterwards, the reflux equipment was adapted for APTES addition $(2 \mathrm{~mL}$ ). Vigorous stirring and reflux under argon atmosphere were kept throughout 3 $\mathrm{h}$ to ensure the siloxane bonds formation. The solids recovered from the organosilylation bottom flask were washed with absolute ethanol (Panreac, $99.9 \%$ wt.) for the removal of the organosilane excess by centrifugation.

Some of the APTES modified materials were subjected to a multi-step grafting process to render in the branched aminosilane, denoted as Acrylate for the remainder of this work, grafted on the external surface. According to the published literature [28], $1 \mathrm{~g}$ of dried APTES- 
functionalized sample was mixed with $78 \mathrm{~mL}$ of ethanol and $15.6 \mathrm{ml}$ of methyl-acrylate (Aldrich, $99 \% \mathrm{wt}$ ) and stirred under $\mathrm{N}_{2}$ flow at room temperature for 3 days. Afterwards, the suspension was filtered and washed with ethanol by centrifugation and dried in a vacuum oven for $12 \mathrm{~h}$ at $110^{\circ} \mathrm{C}$. The resulting solid was mixed with $88 \mathrm{~mL}$ of ethylenediamine (Fluka, $99.5 \% \mathrm{wt}$ ) in $116 \mathrm{~mL}$ of dry methanol (Aldrich, $99.8 \% \mathrm{wt}$ ) and stirred under $\mathrm{N}_{2}$ flow at room temperature for 3 days. Finally, the Acrylate-functionalized solid suspension was filtered and washed with ethanol by centrifugation and dried in a vacuum oven for $12 \mathrm{~h}$ at $110^{\circ} \mathrm{C}$.

\section{Pt Loading Procedures}

Different Pt loading procedures were analysed to identify the most adequate in terms of number and distribution of catalytic sites (see Figure 1). The first method, corresponding to the route a) in Figure 1, is based on the extra framework cation exchange capability of $\mathrm{NaY}$ (FAU) and ETS-10 zeotype with channel diameter 7,4 $\mathrm{A}$ x 7,4 $\AA$ and 4,9 $\mathrm{\AA}$ x 7,6 $\AA$ respectively. Thus, some of the as calcined samples were submitted to a conventional Pt ion-exchange with 0.1 $\mathrm{mM}$ solution of $\left[\mathrm{Pt}\left(\mathrm{NH}_{3}\right)_{4}\right]\left(\mathrm{NO}_{3}\right)_{2}$ (Aldrich, 99,995\%) under gentle stirring for $24 \mathrm{~h}$ at room temperature (15 mg of zeolite per $50 \mathrm{~mL}$ of solution). Next, the powder was washed with DDW by centrifugation to obtain a supernatant conductivity below $20 \mu \mathrm{S}$. Then, the as prepared solids were dried at $60{ }^{\circ} \mathrm{C}$ in an oven. Finally, ion-exchanged powders, denoted as $\mathrm{Pt} / \mathrm{NaY}$ or Pt/ETS-10, were calcined in air for $3 \mathrm{~h}$ at $350^{\circ} \mathrm{C}$ using $0.2^{\circ} \mathrm{C} / \mathrm{min}$ of heating rate; and reduced in $\mathrm{H}_{2}$ atmosphere (10\% vol.) for $3 \mathrm{~h}$ at $350^{\circ} \mathrm{C}$.

The second method, corresponding to the route c) in Figure 1, is based on the interaction between organic groups, such as amino groups, and metal species. Thus, some of the amino functionalized samples were subjected to wet impregnation with Pt precursor solution $\left(\mathrm{H}_{2} \mathrm{PtCl}_{6}\right.$ Aldrich, $8 \%$ wt in water). In a typical experiment, $25 \mathrm{mg}$ functionalized material was dispersed in $25 \mathrm{~mL}$ deionized water. Then, $25 \mathrm{~mL}$ of $\mathrm{H}_{2} \mathrm{PtCl}_{6} \cdot 6 \mathrm{H}_{2} \mathrm{O}$ aqueous solution ( $2 \mathrm{mM}$ ) was added under sonication, using $1 \mathrm{~mL} / \mathrm{min}$ as addition rate; and the 
obtained mixture was stirred for $12 \mathrm{~h}$ at room temperature. Afterwards, $25 \mathrm{~mL}$ of sodium borohydride $\left(\mathrm{NaBH}_{4}\right.$ Aldrich, $99 \%$ wt) solution $10 \mathrm{mM}$ was similarly added under sonication and kept under stirring at room temperature for another $12 \mathrm{~h}$. Thereafter, the activated powders, signed as $\mathrm{NaY} / \mathrm{Pt}$ or ETS-10/Pt, were washed with DDW by centrifugation and dried at $60^{\circ} \mathrm{C}$ in an oven.

The third method, corresponding to the route b) in Figure 1, is a combination of the above mentioned as it involves the impregnation of amino functionalized Pt ion exchanged samples with $\mathrm{H}_{2} \mathrm{PtCl}_{6} \cdot 6 \mathrm{H}_{2} \mathrm{O}$ aqueous solution. The resulting samples were denoted as $\mathrm{Pt} / \mathrm{NaY} / \mathrm{Pt}$ or Pt/ETS-10/Pt respectively.

A summary of the catalytic powders prepared for this work is shown in Table 1, where composition data are also included.

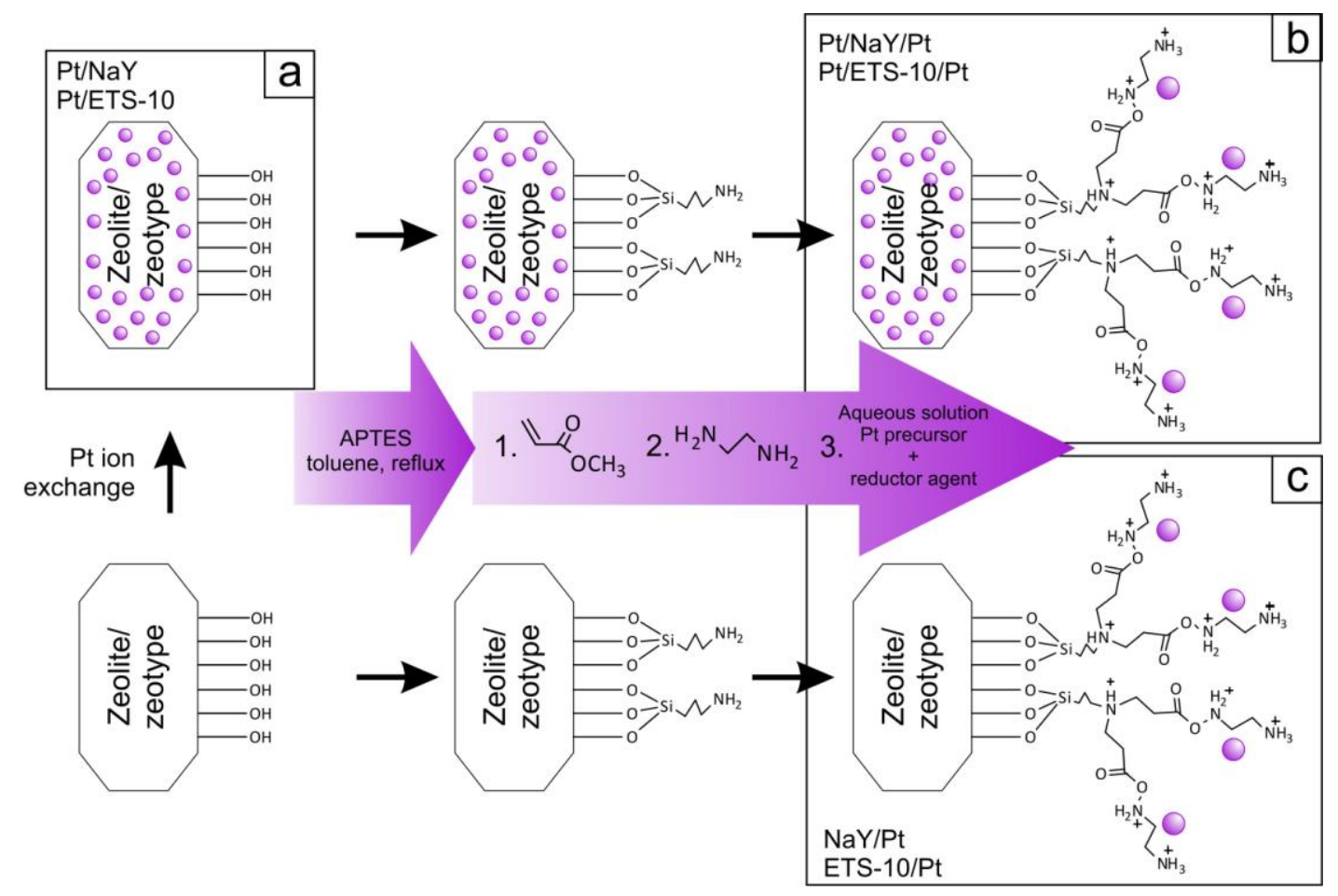

Figure 1. Schematic overview of the preparation routes for the Pt based catalysts studied in this work. 
Table 1. Main Properties of the Pt based catalyts used in this work.

\begin{tabular}{|c|c|c|c|c|c|c|c|}
\hline \multirow{2}{*}{ Sample } & \multicolumn{2}{|c|}{$\begin{array}{c}\text { Surface } \\
\text { Functionalization }\end{array}$} & \multicolumn{3}{|c|}{ Pt Deposition } & \multirow{2}{*}{$\begin{array}{c}\text { Amino- } \\
\text { zeotype ratio } \\
\text { N/Si***(at.) }\end{array}$} & \multirow{2}{*}{$\begin{array}{c}\text { Amino-Pt } \\
\text { ratio } \\
\text { N/Pt**(at.) }\end{array}$} \\
\hline & Organosilane & $\% w^{*}$ & Exchange & Grafting & Pt (\%wt)** & & \\
\hline $\mathrm{Pt} / \mathrm{NaY}$ & - & - & $x$ & & 0,70 & - & - \\
\hline \multirow[b]{2}{*}{$\mathrm{NaY} / \mathrm{Pt}$} & -APTES & 8,7 & & $\mathrm{x}$ & 1,21 & 0,06 & 6,35 \\
\hline & -Acrylate & 12,4 & & $x$ & 2,24 & 0,19 & 11,32 \\
\hline \multirow[b]{2}{*}{$\mathrm{Pt} / \mathrm{NaY} / \mathrm{Pt}$} & -APTES & 6,1 & $x$ & $x$ & 28,18 & 0,05 & 0,19 \\
\hline & -Acrylate & 13,5 & $x$ & $x$ & 2,05 & 0,21 & 13,47 \\
\hline Pt/ETS-10 & - & - & $x$ & & 0,85 & & \\
\hline \multirow[b]{2}{*}{ ETS-10/Pt } & -APTES & 4,9 & & $x$ & 1,99 & 0,03 & 2,17 \\
\hline & -Acrylate & 10,1 & & $x$ & 5,52 & 0,13 & 3,74 \\
\hline \multirow[b]{2}{*}{$\mathrm{Pt} / \mathrm{ETS}-10 / \mathrm{Pt}$} & -APTES & 3,0 & $x$ & $x$ & 23,15 & 0,02 & 0,11 \\
\hline & -Acrylate & 5,2 & $x$ & $x$ & 1,95 & 0,06 & 5,45 \\
\hline
\end{tabular}

*organosilane loading estimated by TGA; ** Pt evaluated by AAS, ***Si from the microporous support. 


\section{Characterization Techniques and Activity Tests for Catalytic Powders}

A battery of techniques was used to characterize the catalysts. The amount of Pt incorporated was determined by absorption emission spectroscopy (SpectraAA 110 Varian, with a Pt lamp working at $\lambda=265.9 \mathrm{~nm}$ ) after digestion with aqua regia in a microwave oven (Milestone Ethos Plus). The morphology and particle size distribution of Pt in the microporous supports was measured by transmission electron microscopy (FEI Tecnai T20, operating at 200 kV). The purity and crystallinity were studied by X-ray diffraction (Rygaku/Max System RU 300). ATR-FTIR analyses (VERTEX 70 equipment with microscope slide MKII Golden Gate ATR from 4000 to $600 \mathrm{~cm}^{-1}, 256$ scans and resolution of $0.05 \mathrm{~cm}^{-1}$ ) were performed to assess about the goodness of the organosilylation process. Additionally, thermogravimetric analyses (TGA) from room temperature up to $900^{\circ} \mathrm{C}$ under $\mathrm{N}_{2}$ flow and using $1^{\circ} \mathrm{C} / \mathrm{min}$ as heating rate, were also performed with a Q5000 IR (TA Instruments) to quantify the amination degree.

Electro-oxidation of $\mathrm{CO}$ was performed to (i) confirm the presence of electroactive $\mathrm{Pt}$ sites and (ii) estimate the electrochemical active surface area (EAS) of the Pt based catalysts. Cyclic voltammograms were recorded between $0.01 \mathrm{~V}$ and $1.20 \mathrm{~V}$ vs. RHE at a scan rate of 20 $\mathrm{mVs}^{-1}$ and room temperature. CO stripping was conducted after bubbling this gas in the cell for $10 \mathrm{~min}$ at $0.20 \mathrm{~V}$, followed by nitrogen purging to remove the excess of CO. A factor of $420 \mu \mathrm{C}$ $\mathrm{cm}^{-2}$ has been considered for conversion of charge to electrochemical surface area (ECAS) of platinum. The electrochemical experiments were performed using an Autolab PGSTAT 101 potentiostat controlled by a dedicated software packages NOVA 1.8 in a standard threeelectrode Pyrex cell following the methods reported in literature [29]. As counter electrode was used a graphite rod and as reference electrode was used a reversible hydrogen electrode (RHE). A thin layer of the electrocatalyst was deposited on the glassy carbon disk $(7 \mathrm{~mm}$ in diameter) working electrode. For such purposes, a suspension of the Pt based catalyst was 
prepared by ultrasonication of $2 \mathrm{mg}$ of catalyst powder in $15 \mu \mathrm{l}$ of Nafion (Aldrich, $15 \% \mathrm{wt}$ in water) and $500 \mu \mathrm{l}$ DDW. An aliquot of $40 \mu \mathrm{L}$ of suspension was deposited on the top of graphite disk and dried. Dilute liquid electrolytes, $0.5 \mathrm{M} \mathrm{H}_{2} \mathrm{SO}_{4}$, were degassed by purging $\mathrm{N}_{2}$ for $3 \mathrm{~h}$ prior to every measurement.

The catalytic powders $(25 \mathrm{mg})$, diluted with ground quartz $(25 \mathrm{mg})$, were tested in a quartz fixed-bed reactor ( $6 \mathrm{~mm}$ in diameter) for the catalytic combustion of $\mathrm{n}$-hexane as model pollutant. The total gas flow rate was $30 \mathrm{~N} \mathrm{~mL} / \mathrm{min}$ corresponding to a WHSV 72000 $\mathrm{mL} / \mathrm{h} \cdot \mathrm{g}_{\mathrm{pt}+\text { support, }}$ and the concentration of $\mathrm{n}$-hexane was $200 \mathrm{ppm}$. The catalysts were tested at predetermined temperatures, starting from $100{ }^{\circ} \mathrm{C}$. Before measurements, the catalyst was stabilized at each temperature for $150 \mathrm{~min}$ to ensure stable conversion. The gases were analyzed by online gas chromatography (Agilent 3000 Micro GC) with 3 ppm as detection limit for $n$-hexane. Mass balance closures were $\pm 2 \%$ and no partial oxidation products were detected.

\section{PBI Microsieves prepared by Microtransfer Molding}

Microtransfer molding technique has been used to prepare PBI microsieves from a relief pattern of poly (dimethylsiloxane) (PDMS) mold according to our previous work [21]. Firstly, master was fabricated with the negative photoresist SU8 by one photolithographic process. A layer of SU-8 was deposited by spin-coating at $3000 \mathrm{rpm}$ for $15 \mathrm{~s}$, on a 4-in $\mathrm{SiO}_{2}$-coated Si wafer. SU-8 2025 (MicroChem) was used to obtain layers with thicknesses up to $20 \mu \mathrm{m}$. Following a soft bake step at $95{ }^{\circ} \mathrm{C}$ for $6 \mathrm{~min}$, the SU-8 layer was exposed to UV light through a mask for $8 \mathrm{~s}$. A post exposure bake at $95{ }^{\circ} \mathrm{C}$ for 5 min was then carried out, before developing the SU-8 in propylene glycol methyl ether acetate (PGMEA), to obtain the master.

PDMS prepolymer solution was made by thoroughly mixing the silicon elastomer (Sylgard ${ }^{\circledR} 184$ supplied by Dow Corning) and the curing agent 184 in a 10:1 (v:v) ratio. The mixture was put under vacuum to remove air bubbles. Then, it was carefully poured onto the 
SU-8 master to cover its entire area, and finally cured at $80^{\circ} \mathrm{C}$ for $30 \mathrm{~min}$. The fabricated PDMS mold was peeled off the master with the aid of tweezers and stored in a closed container under clean room conditions. As a result, a PDMS mold 4-in in diameter containing the desired patterns, i.e. pillars $10 \mu \mathrm{m}$ wide separated by $20 \mu \mathrm{m}$, was obtained.

The PBI microsieves were prepared by casting of a PBI solution onto the PDMS mold at $60^{\circ} \mathrm{C}$, followed by solvent evaporation at $90^{\circ} \mathrm{C}$ (heating rate $10^{\circ} \mathrm{C} / \mathrm{h}$ ) during $12 \mathrm{~h}$. The PBI solution was prepared following the procedures already described for PBI dense membranes [14]. Particularly, a PBI solution 1.6\% wt in N-N dimethylacetamide (DMAc) (Aldrich, $99.8 \% \mathrm{wt}$ ) solution was used to improve the mold soaking. The fabricated PBI microsieve, circa $20 \mu \mathrm{m}$ thick, was easily released from the elastomeric substrate. A direct pattern transfer from SU8 mold to PBI was discarded due to the high chemical affinity between SU8 resin (epoxy groups) and $\mathrm{PBI}$ (amine groups). Before use, the PBI microsieve was cut in circular pieces $20 \mathrm{~mm}$ in diameter containing the desired patterns, i.e. $20 \mu \mathrm{m}$ holes separated by $10 \mu \mathrm{m}$ distance.

\section{PBI Micromonolith-type Stack}

The PBI micromonolith-type stack was prepared by the assembly of five PBI circular microsieves $20 \mathrm{~mm}$ in diameter. Each microsieve was allocated between two dense PBI annular rings (22 mm-14 mm as external and internal diameter respectively) and glued with PBI solution. Finally, the resulting PBI micromonolith-type stack was pressed between two teflon holders at $90^{\circ} \mathrm{C}$ for $3 \mathrm{~h}$.

\section{Catalyst Anchoring on PBI Micromonoliths}

PBI membranes coated with functionalized microporous crystals by covalent linkage have been already described by our group for fuel cell applications [10]. The as reported chemical seeding is based on the secondary amine chemistry due to - $\mathrm{NH}$-imidazole ring. Following a similar procedure, epoxy functionalized ETS-10 crystals were firstly coupled to the 
benzimidazole ligand (see Figure 2.A). Thus, the epoxy groups lying on the PBI surface could play as connectors to the surface amino groups of the Pt supported catalysts. To this end, the epoxy functionalized PBI micromonolith was immersed in $50 \mathrm{~mL}$ of toluene containing ETS10/Pt catalysts (40 mg) under sonication and kept for $5 \mathrm{~min}$. After washing with fresh toluene, the procedure was repeated twice to increase the Pt catalyst loading. Finally, the activated PBI micromonolith was dried at $120^{\circ} \mathrm{C}$ overnight.

Furthermore, the presence of benzimidazole reactive groups also enables the direct immobilisation of Pt nanoparticles (see Figure 2.B) in a similar way to the reported for Pd and resin type polymers containing methyl-imidazole moieties [30]. According to the literature, this additional anchoring pathway would improve the capture and stabilization of the active metal species.

\section{Characterization Techniques and Activity Tests for Catalytic PBI Micromonoliths}

Thermogravimetric analyses (TGA) from room temperature up to $900^{\circ} \mathrm{C}$ under $\mathrm{N}_{2}$ flow and using $1^{\circ} \mathrm{C} / \mathrm{min}$ as heating rate were performed to evaluate the catalyst loading on the PBI microsieve. A comprehensive morphological examination by SEM of the PBI micromonolithtype stack step by step throughout the whole preparation procedure and after catalytic testing was carried out. The activated PBI micromonolith-type stack was studied for the catalytic abatement of $\mathrm{n}$-hexane under similar conditions to those employed for powder materials ( 30 $\mathrm{NmL} /$ min corresponding to a WHSV $65400 \mathrm{~mL} / \mathrm{h} \cdot \mathrm{g}_{\mathrm{Pt} t \text { support }}$, and $200 \mathrm{ppm}$ as inlet concentration). For such purposes, the micromonolith was properly assembled and sealed on a reaction chamber following the procedures already described in our previous works [26-27]. 


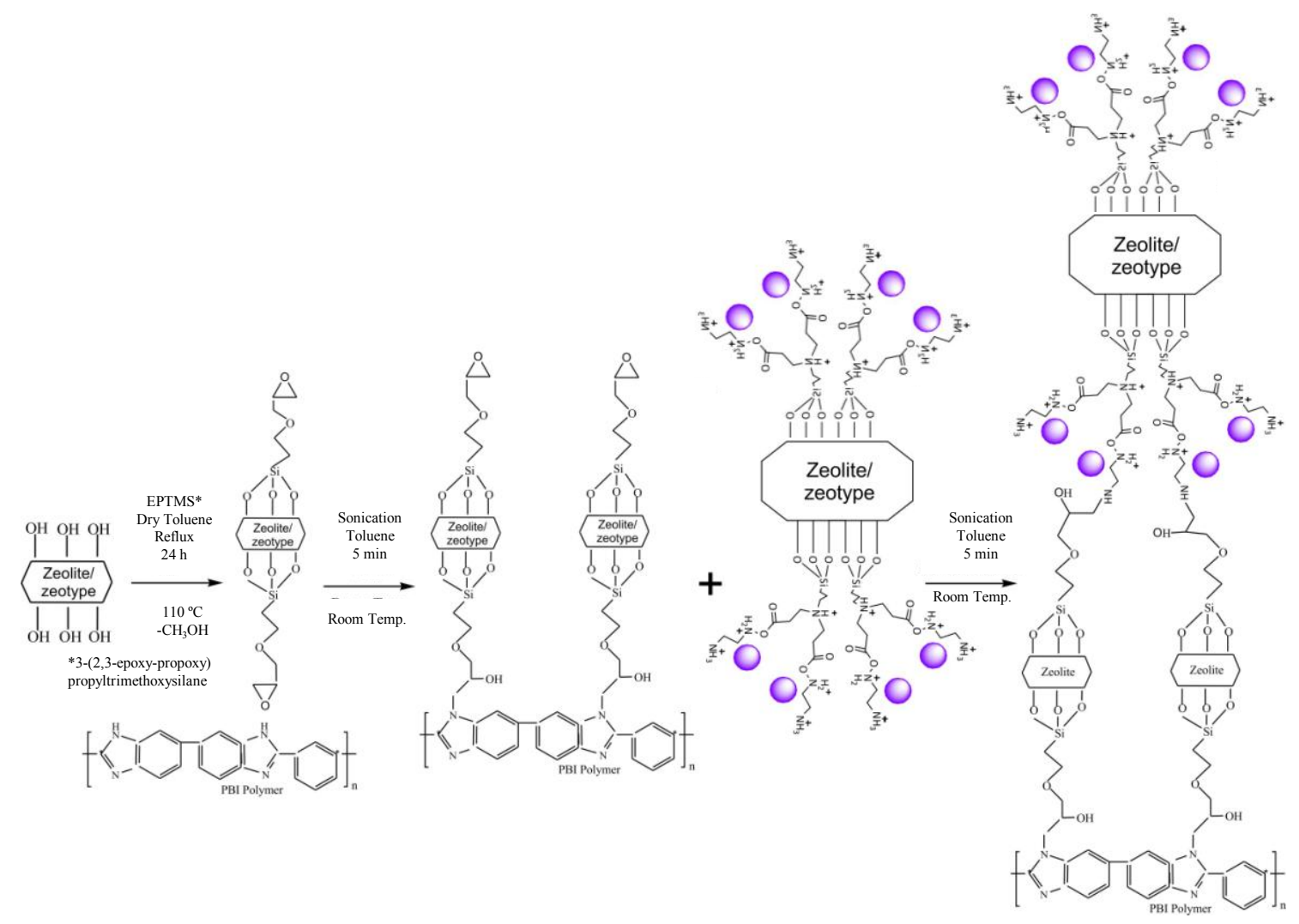

Figure 2.A) General Scheme for the Pt based catalysts anchoring on the PBI surface by means of epoxi functionalized microporous connectors.

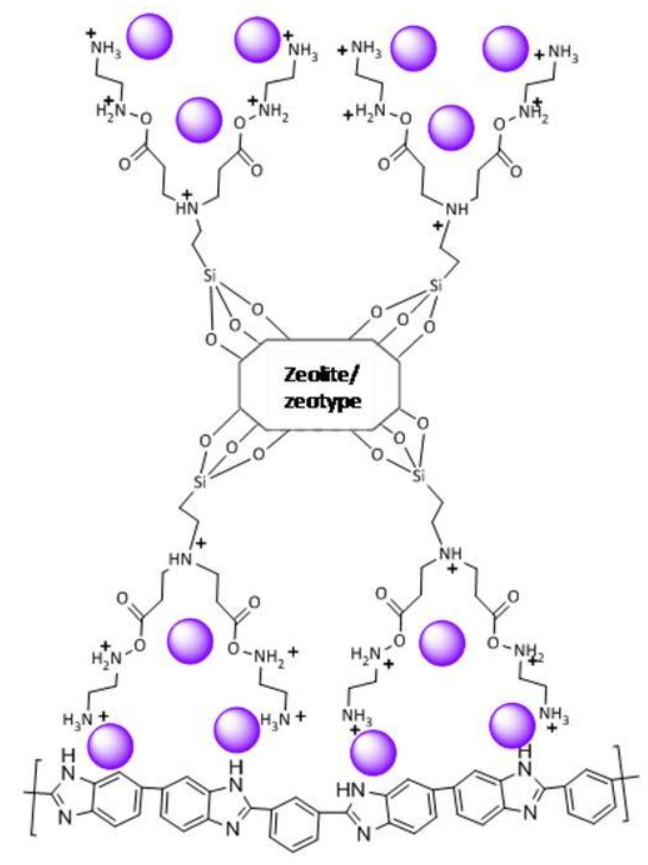

Figure 2.B) General Scheme for the Pt based catalysts anchoring on the as prepared PBI by means of benzimidazole ligand. 


\section{Results \& Discussion}

\section{Pt-based catalysts in powder form}

The success of the amino grafting has been evaluated by ATR-FTIR and TGA. As an example, Figure 3.A shows comparatively the spectra of ETS-10 crystals before and after the multi-step functionalization with Acrylate. In particular, IR characteristic bands assigned to $C=0$ stretching $\left(1670 \mathrm{~cm}^{-1}\right), \mathrm{NH}_{2}$ deformation $\left(1650-1590 \mathrm{~cm}^{-1}\right)$ and $\mathrm{NH}_{3}{ }^{+}$deformation (1600-1480 $\mathrm{cm}^{-1}$ ) appear after the grafting procedure. ATR-FTIR spectra in the $1650-1600 \mathrm{~cm}^{-1}$ also reveals the presence of physisorbed water, more pronounced for pristine ETS-10.

Similarly, TG analyses before and after amination process are shown in Figure 3.B where differential curves have been depicted and deconvolutioned. The first weight loss could be associated to organics desorption and weakly-bound water. Unlike as synthesized ETS-10 crystals, this water removal is extended up to higher temperature values $\left(300^{\circ} \mathrm{C}\right)$ for the functionalized sample. A thermal decomposition event at $420^{\circ} \mathrm{C}$ associated to the organosilane removal-decomposition is clearly distinguished for ETS-10-Acrylate sample. Accordingly, the amount of organosilane (referred to dry solid) attached to the external surface of the microporous crystals has been estimated and tabulated (see Table 1). It should be noticed that the registered temperature values related to the grafted organics are in accordance with the exhibited thermal and chemical stability of the functionalized samples under reaction conditions.
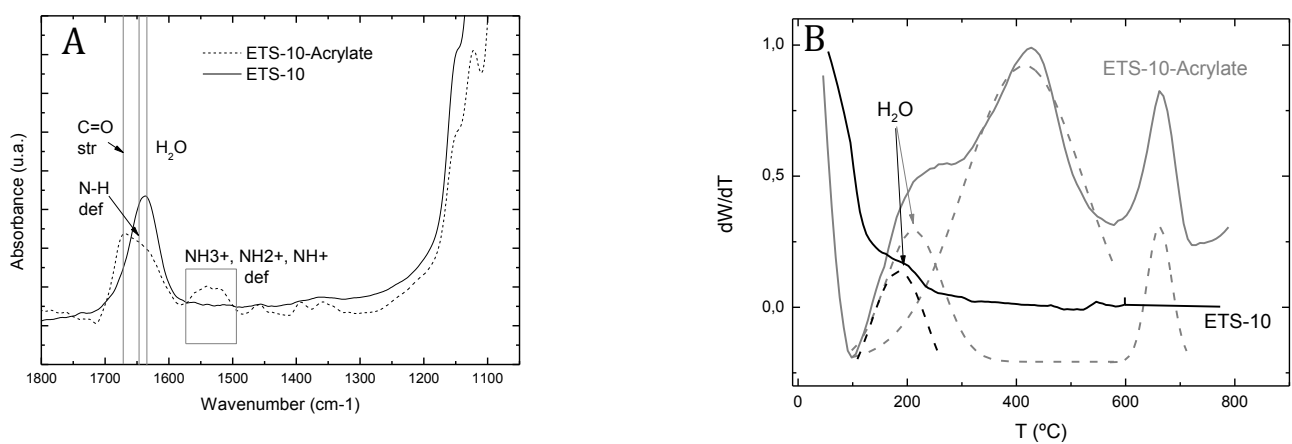
Figure 3.A) ATR-FTIR analyses, and B) TGA for $\mathrm{Na} / \mathrm{K}$ ETS-10 crystals before and after amino grafting with Acrylate.

Seen from Table 1, the organosilane loadings for samples functionalized with aAcrylate are higher than for APTES counterparts. As an example, the ETS-10/Pt and NaY/Pt samples prepared according to the second method (route $c$ in Figure 1 ) exhibit $10,1 \% w t$ and $12,4 \% w t$ when functionalized with Acrylate versus 4,9 \%wt and 8,7 \%wt for APTES modification, respectively. Considering the molecular weight of both organosilanes, the APTES grafting degree has been slightly higher due to the steric effects associated to the branched structure of the Acrylate molecule. However, from the calculated amino-zeotype ratio, expressed as N:Si atomic ratio (see Table 1); the Acrylate modified samples contain more amino groups than APTES counterparts in accordance with the N:Si atomic ratio of the grafted organosilanes $(5: 1$ for Acrylate versus 1:1 for APTES).

The samples prepared according to method 3 (route b) in Figure 1), a combination of ion-exchange and grafting processes, exhibited lower organosilane loadings. This distinct behaviour is related to the zeta potential for the negatively charged Pt ion-exchanged samples. Thus, after impregnation with $\left[\mathrm{Pt}\left(\mathrm{NH}_{3}\right)_{4}\right]\left(\mathrm{NO}_{3}\right)_{2}$ solution, the recovered solids exhibit lower zeta potential due to the presence of $\left[\mathrm{Pt}\left(\mathrm{NH}_{3}\right)_{4}\right]^{2+}$ species on the external surface capable to interact with $-\mathrm{OH}$ groups from the microporous support. Consequently, the number of available silanol groups for the subsequent covalent linkage with aminosilanes is lower in agreement with the data reported in Table 1. As an example, the Pt/ETS-10/Pt and Pt/NaY/Pt samples exhibit 3,0 \%wt and 6,1 \%wt, respectively when functionalized with APTES.

The Pt contents for ion-exchanged samples (route a) in Figure 1) are in accordance with those previously reported for such microporous materials $[22,26]$. The degree of exchange for Pt/ETS-10 and Pt/NaY are around $1.83 \%$ and $2.20 \%$ respectively. 
All the amino functionalized samples have high Pt loadings, more than $1 \%$ wt (estimated by AAS), as it was expected; owing to the interaction between the metal ions and the organic groups. In particular, for a given catalytic system and preparation method 2 (route c) in Figure 1), the higher amino-zeotype ratio, the higher Pt loading. Thus, the loading capability of Acrylate based samples is larger than that of APTES counterparts. As an example, Pt loadings for ETS-10/Pt and NaY/Pt samples are 5,52 \%wt and 2,24\%wt when functionalized with Acrylate versus 1,99\%wt and 1,21 \%wt for APTES modification.

A quite distinct behaviour is exhibited by Pt samples prepared by method 3 (route b) in Figure 1), a combination of ion-exchange and grafting processes. Particularly for APTES modified samples, the metal species loosely attached to the external surface after ionexchange and subsequently reduced at $350^{\circ} \mathrm{C}$, act as nucleation seeds for the subsequent $\mathrm{Pt}$ anchoring over the aminated surface. Thus, Pt loadings as large as $23,15 \% w t$ and $28,18 \% w t$ are shown by $\mathrm{Pt} / \mathrm{ETS}-10 / \mathrm{Pt}$ and $\mathrm{Pt} / \mathrm{NaY} / \mathrm{Pt}$ samples respectively. On the contrary, the $\mathrm{Pt}$ seeding effect is almost negligible for Acrylate counterparts due to the successive washing of the multi-step grafting. As a matter of fact, Pt loadings are 1,95\%wt and 2,05\%wt for Pt/ETS10/Pt and $\mathrm{Pt} / \mathrm{NaY} / \mathrm{Pt}$, respectively.

In this work, the Pt dispersion has been correlated with the electrochemical surface area (ECAS) for CO oxidation, expressed in $\mathrm{cm}^{2} / \mathrm{mg}_{\mathrm{pt}}$, for some of the as prepared solids (see Table 2). It has been indicated in the literature than Pt colloidal nanoparticles outperform conventional heterogenous catalysts in CO oxidation. As a matter of fact, the lower ECAS values are exhibited by Pt-exchanged samples, i.e. $3,3 \mathrm{~cm}^{2} / \mathrm{mg}_{\mathrm{Pt}}$ and $7,5 \mathrm{~cm}^{2} / \mathrm{mg}_{\mathrm{Pt}}$ for Pt/ETS10 and $\mathrm{Pt} / \mathrm{NaY}$ respectively. Accounting from the tabulated ECAS, the structure of the aminosilane grafted molecules seems to play a significant role. A remarkable beneficial effect on Pt dispersion is noticed for samples modified with the branched acrylate-organosilane. As an example, the exhibited ECAS values for ETS-10/Pt are $104,4 \mathrm{~cm}^{2} / \mathrm{mg}_{\mathrm{pt}}$ and $421,3 \mathrm{~cm}^{2} / \mathrm{mg}_{\mathrm{pt}}$ when functionalized with APTES and Acrylate respectively. Similarly, the recorded ECAS for 
$\mathrm{Pt} / \mathrm{NaY} / \mathrm{Pt}$ samples are $6,7 \mathrm{~cm}^{2} / \mathrm{mg}_{\mathrm{Pt}}$ and $61,7 \mathrm{~cm}^{2} / \mathrm{mg}_{\mathrm{Pt}}$ when functionalized with APTES and Acrylate, respectively. Accordingly, samples prepared by the multistep grafting, i.e. Acrylatebased, seem to be the most adequate for metal active sites distribution, i.e. Pt utilization.

Table 2. Catalytic properties for some of the as catalysts prepared in this work.

\begin{tabular}{|c|c|c|c|c|c|}
\hline \multirow[b]{2}{*}{ Sample } & \multicolumn{5}{|c|}{ Preparation Method 1} \\
\hline & Organosilane & Ion Exchange & Grafting & $\begin{array}{c}\mathrm{ECAS}_{\mathrm{CO}} \\
\left(\mathrm{cm}^{2} / \mathrm{mg} \mathrm{Pt}\right)\end{array}$ & $\begin{array}{l}\text { n-Hexane combustion rate } \\
\left(\mu \mathrm{mol} / \mathrm{h} \cdot \mathrm{mg}_{\mathrm{Pt}}\right) \text { at } 175^{\circ} \mathrm{C}\end{array}$ \\
\hline $\mathrm{Pt} / \mathrm{NaY}$ & -- & $x$ & & 7,5 & 1,68 \\
\hline Pt/ETS-10 & -- & $x$ & & 3,3 & 3,20 \\
\hline \multirow[b]{2}{*}{ Sample } & \multicolumn{5}{|c|}{ Preparation Method 2} \\
\hline & Organosilane & Ion Exchange & Grafting & $\begin{array}{c}\mathrm{EAS}_{\mathrm{CO}} \\
\left(\mathrm{cm}^{2} / \mathrm{mg} \mathrm{Pt}\right)\end{array}$ & $\begin{array}{c}\text { n-Hexane combustion rate } \\
\left(\mu \mathrm{mol} / \mathrm{h} . \mathrm{g}_{\mathrm{Pt}}\right) \text { at } 175^{\circ} \mathrm{C}\end{array}$ \\
\hline \multirow{2}{*}{$\mathrm{NaY} / \mathrm{Pt}$} & -APTES & & $x$ & n.a. & n.a. \\
\hline & -Acrylate & & $x$ & 64,9 & 6,51 \\
\hline \multirow{2}{*}{ ETS-10/Pt } & -APTES & & $x$ & 104,4 & n.a. \\
\hline & -Acrylate & & $x$ & 421,3 & 10,65 \\
\hline \multirow[b]{2}{*}{ Sample } & \multicolumn{5}{|c|}{ Preparation Method 3} \\
\hline & Organosilane & Ion Exchange & Grafting & $\begin{array}{c}\mathrm{EAS}_{\mathrm{CO}} \\
\left(\mathrm{cm}^{2} / \mathrm{mg} \mathrm{Pt}\right)\end{array}$ & $\begin{array}{r}\text { n-Hexane combustion rate } \\
\left(\mu \mathrm{mol} / \mathrm{h} . \mathrm{mg}_{\mathrm{Pt}}\right) \text { at } 175^{\circ} \mathrm{C}\end{array}$ \\
\hline \multirow{2}{*}{$\mathrm{Pt} / \mathrm{NaY} / \mathrm{Pt}$} & -APTES & $x$ & $x$ & 6,7 & n.a. \\
\hline & -Acrylate & $x$ & $x$ & 61,7 & 15,09 \\
\hline \multirow{2}{*}{ Pt/ETS-10/Pt } & -APTES & $x$ & $x$ & n.a. & n.a. \\
\hline & -Acrylate & $x$ & $x$ & n.a. & 14,34 \\
\hline
\end{tabular}


TEM analyses have been performed on Acrylate modified samples to asses about Pt dispersion and particle size distribution. The results are presented in Figure 4 and Figure 5 for $\mathrm{NaY}$ and ETS-10 supports respectively. The cluster size distribution is given as an inset for each figure. A minimum of 100 particles are measured in each micrograph.The behaviour exhibited by $\mathrm{Pt} / \mathrm{NaY}$ exchanged sample (method 1 ) is in accordance to the previously described [22] with an average size of $0.83 \pm 0.07 \mathrm{~nm}$. In the case of Pt/ETS-10, Pt particles with an average size of $\mathrm{d}=2.02 \pm 0.28 \mathrm{~nm}$ outside the microporous structure are evident, in accordance with the low pore size of this zeotype [31]. Samples prepared according to method 3 (route b) in Figure 1) have larger average size $(d=4.02 \pm 0.39 \mathrm{~nm}$ for Pt/ETS-10/Pt and $d=2.79 \pm 1.04 \mathrm{~nm}$ for $\mathrm{Pt} / \mathrm{NaY} / \mathrm{Pt}$ ) and worse dispersion leading to obvious aggregation of $\mathrm{Pt}$ nanoparticles. This observation is quite noticeable for $\mathrm{Pt} / \mathrm{NaY} / \mathrm{Pt}$. The authors hypothesized that the acidity change due to Pt extra-framework cations results in the formation of larger particles. On the contrary, samples prepared according to method 2 (route c) in Figure 1) exhibit higher Pt dispersion. Particularly noteworthy is sample ETS-10/Pt with metal loading up to $5.52 \% \mathrm{wt}$ exhibiting an average diameter of $3.67 \pm 0.23 \mathrm{~nm}$. Indeed, the highest ECAS for CO oxidation $\left(421,3 \mathrm{~cm}^{2} / \mathrm{mg}_{\mathrm{pt}}\right)$ corresponds to this catalyst. The above results reveal that both the structure and composition of the microporous support have effect on size and dispersion of $\mathrm{Pt}$ nanoparticles.

Precisely, XRD analysis of ETS-10/Pt sample is shown in Figure 6. The presence of anatase impurities at $2 \theta=25.3$ (labeled in Figure 6) could be clearly identified. Moreover, the typical cubic structure (fcc) of Pt is observed. The mean crystallite size derived from Pt (220) peak broadening is $6.02 \mathrm{~nm}$, slightly higher than the observed by TEM. 

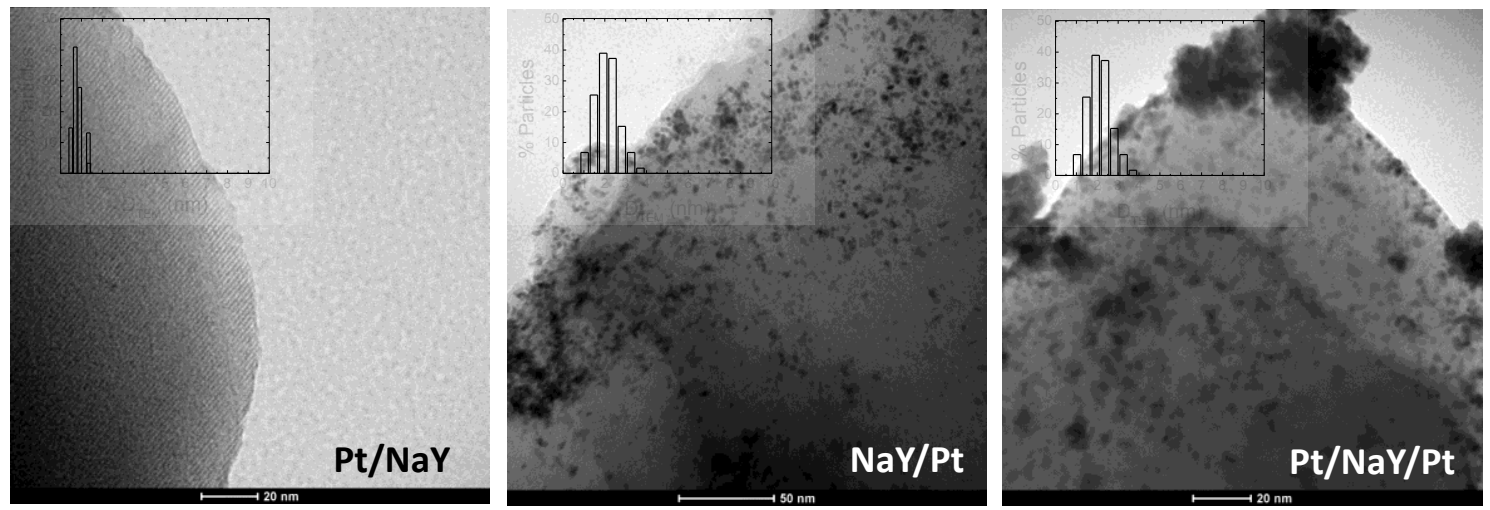

Figure 4. TEM analyses for the catalytic powders based on NaY.
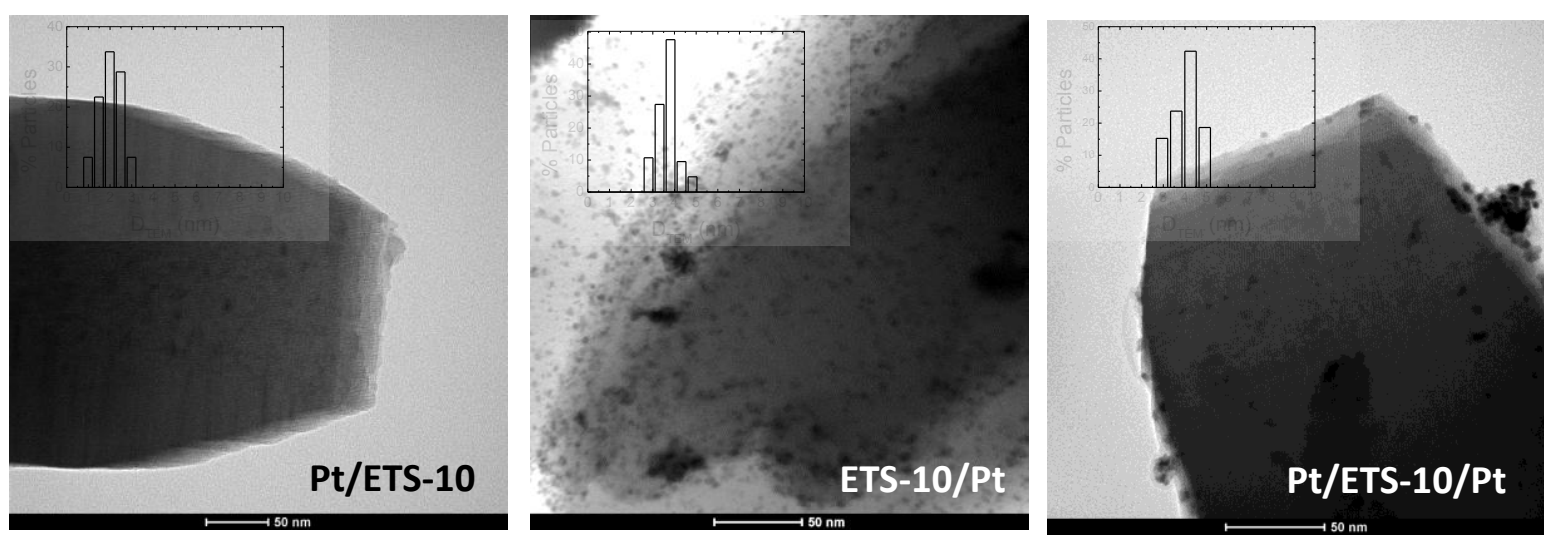

Figure 5. TEM analyses for the catalytic powders based on ETS-10.

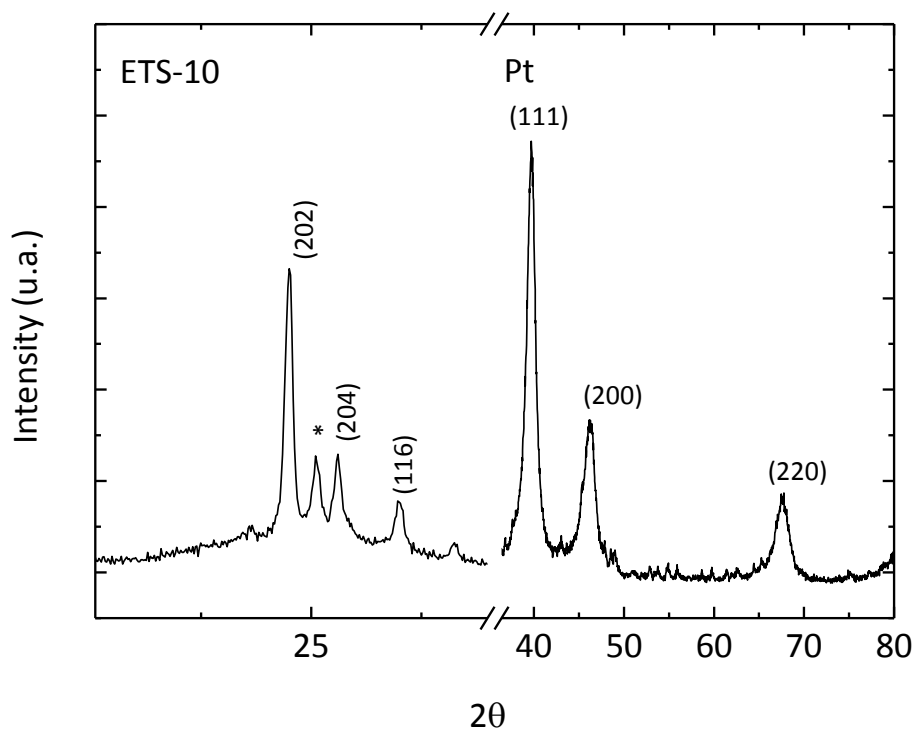

Figure 6. XRD analysis for ETS-10/Pt catalyst. 
Catalytic properties of Pt on acrylate modified supports are investigated on $\mathrm{n}$-hexane combustion at ppm level and compared to those exhibited by ion-exchange samples. Figures 7.A) and 7.B) show light-off results over NaY and ETS-10 supports, respectively. Known from Table 2, the catalytic activity towards VOC abatement follows the same trend to the exhibited for electrochemical oxidation of $\mathrm{CO}$ : the higher the ECAS values the lower the temperatures required for a given VOC conversion. Thus, ETS-10/Pt sample, with 5.52\% wt. Pt loading and $421,3 \mathrm{~cm}^{2} / \mathrm{mg}_{\mathrm{Pt}}$ as $\mathrm{ECAS}_{\mathrm{CO}}$ will benefit good catalytic performance. As a matter of fact, the temperature values requiered for $50 \%$, ( $T_{50}$ or light-off temperature) and $90 \%\left(T_{90}\right)$ conversion are $142^{\circ} \mathrm{C}$ and $175^{\circ} \mathrm{C}$ respectively. It can be seen that its light-off curve is shifted around $45^{\circ} \mathrm{C}$ lower than NaY/Pt counterpart. To get a proper comparison of the catalysts performance, due to the total Pt load is somewhat higher for ETS-10/Pt; Table 2 includes the $n$-hexane combustion rate at $175^{\circ} \mathrm{C}$ expressed per mg of Pt. Thus, not only VOC conversion capability but also specific reaction rate, have been considered to identify ETS-10/Pt sample as the outperforming catalyst for further deployment on PBI micromonoliths.
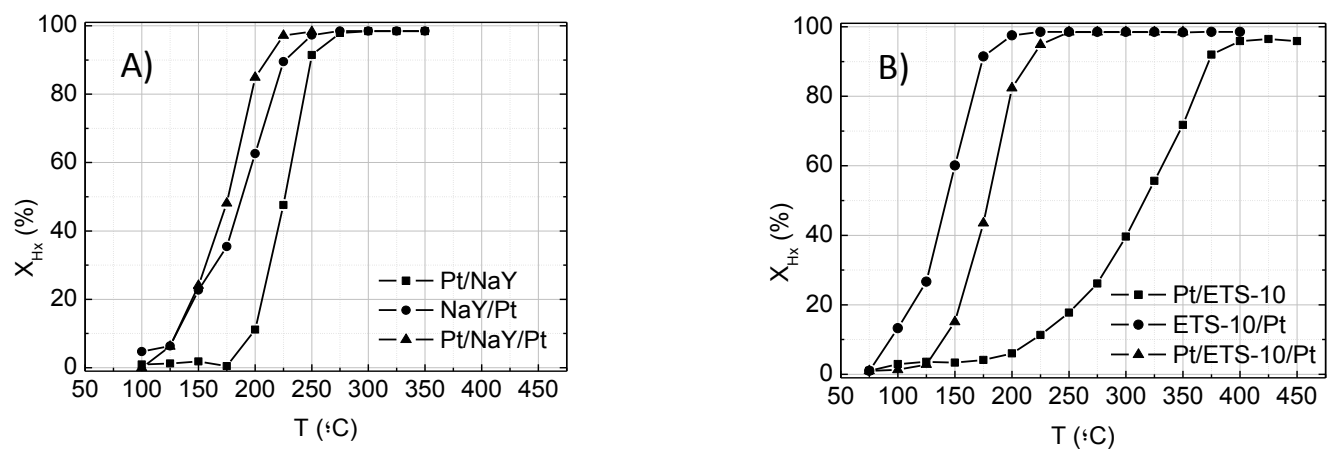

Figure 7. Light-off curves of Pt based catalysts supported on: A) NaY, and B) ETS-10 materials. Reaction conditions: $200 \mathrm{ppmV} \mathrm{n}$-hexane, WHSV $72000 \mathrm{~mL} / \mathrm{h} \cdot \mathrm{g}$ Pt+support, contact time $565 \mathrm{~ms}$. 


\section{Pt-based Catalytic Coatings on PBI micromonolith-type stack}

The relative high $\mathrm{N}: \mathrm{Pt}$ atomic ratio(higher than the stoichiometric value for $\left[\mathrm{PtCl}_{6}\right]^{2-}$ and $\left[-\mathrm{NR}_{2}\right]^{+}$reaction) exhibited by the Acrylate grafted catalysts (see Table 1 ), would indicate an excess of surface $-\mathrm{NH}$ groups available for further interactions. Thus, our proposed activation process for the PBI micromonolith involves the following multi-step grafting: firstly with epoxyfunctionalized microporous crystals by means of benzimidazole ligand; and secondly, with Acrylate modified Pt based catalysts by means of epoxy-amino linkage. Moreover, the direct capture of the catalysts thanks to the interaction between Pt nanoparticles and benzimidazole from the PBI backbone is an additional contribution for the activation of the microstructured PBI.

Before carrying out the PBI coating, the epoxy functionalization process on $\mathrm{NaY}$ and ETS10 microporous supports is firstly studied. Figures 8.A and 8.B show comparatively the spectra of NaY and ETS-10 crystals before and after the grafting process. Unlike ETS-10 samples, the epoxy functionalization clearly fails for $\mathrm{NaY}$ support due to its remarkable hydrophilic properties. In contrast, IR characteristic bands assigned to C-O stretching (1290-1250 cm ${ }^{-1}$ ) $\mathrm{CH}_{2}$ - deformation $\left(1450 \mathrm{~cm}^{-1}\right)$ and asymmetric stretching $\left(2980-2840 \mathrm{~cm}^{-1}\right)$ appear after the grafting procedure over ETS-10. 
A)
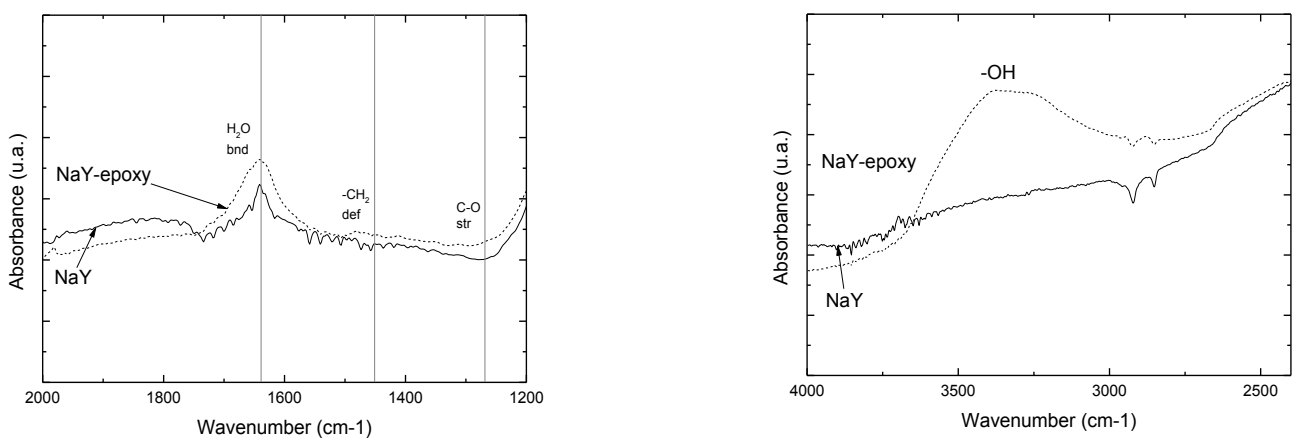

B)
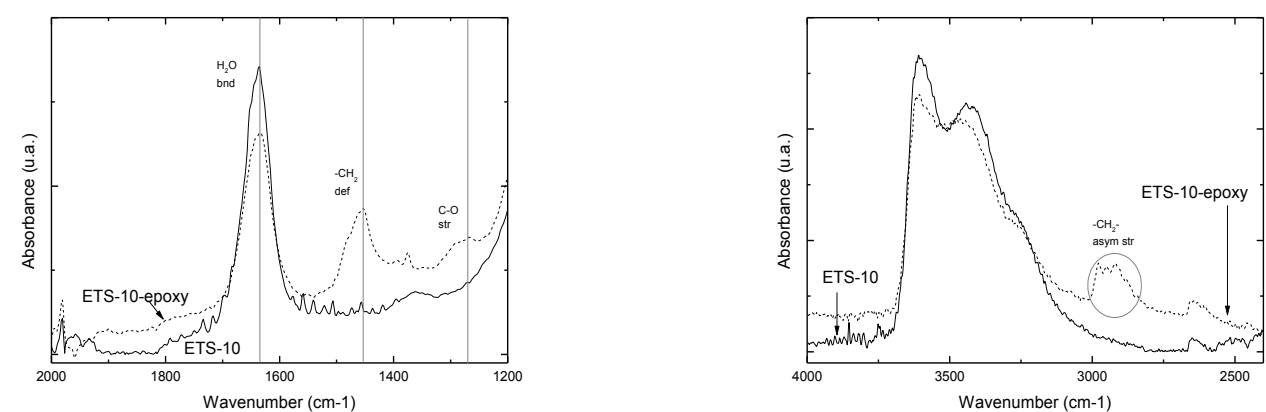

Figure 8. ATR-FTIR analyses of epoxi functionalized: A) NaY, and B) ETS-10 type supports.

Accounting from the above results, the as prepared $\mathrm{PBI}$ micromonolith-type stack comprising 5 PBI microsieves $20 \mu \mathrm{m}$ thick has been subjected to the catalytic activation with ETS-10/Pt catalyst following the scheme shown in Figure 9. Its worthwhile to mention that the second grafting step is performed three times to enhance ETS-10/Pt loading on the PBI microchannels. An homogeneous coverage degree of the PBI stack with S/V ratio of $70000 \mathrm{~m}^{-1}$ is ascertained from the top and cross section views by SEM depicted in Figure 10.A. TGA results, not shown here, indicate ETS-10/Pt loadings around $5 \mathrm{mg}$ per $\mathrm{cm}^{2}$; that means $27,5 \mathrm{mg}$ and 1,49 mg of catalyst and Pt per PBI micronolith-type stack respectively. 


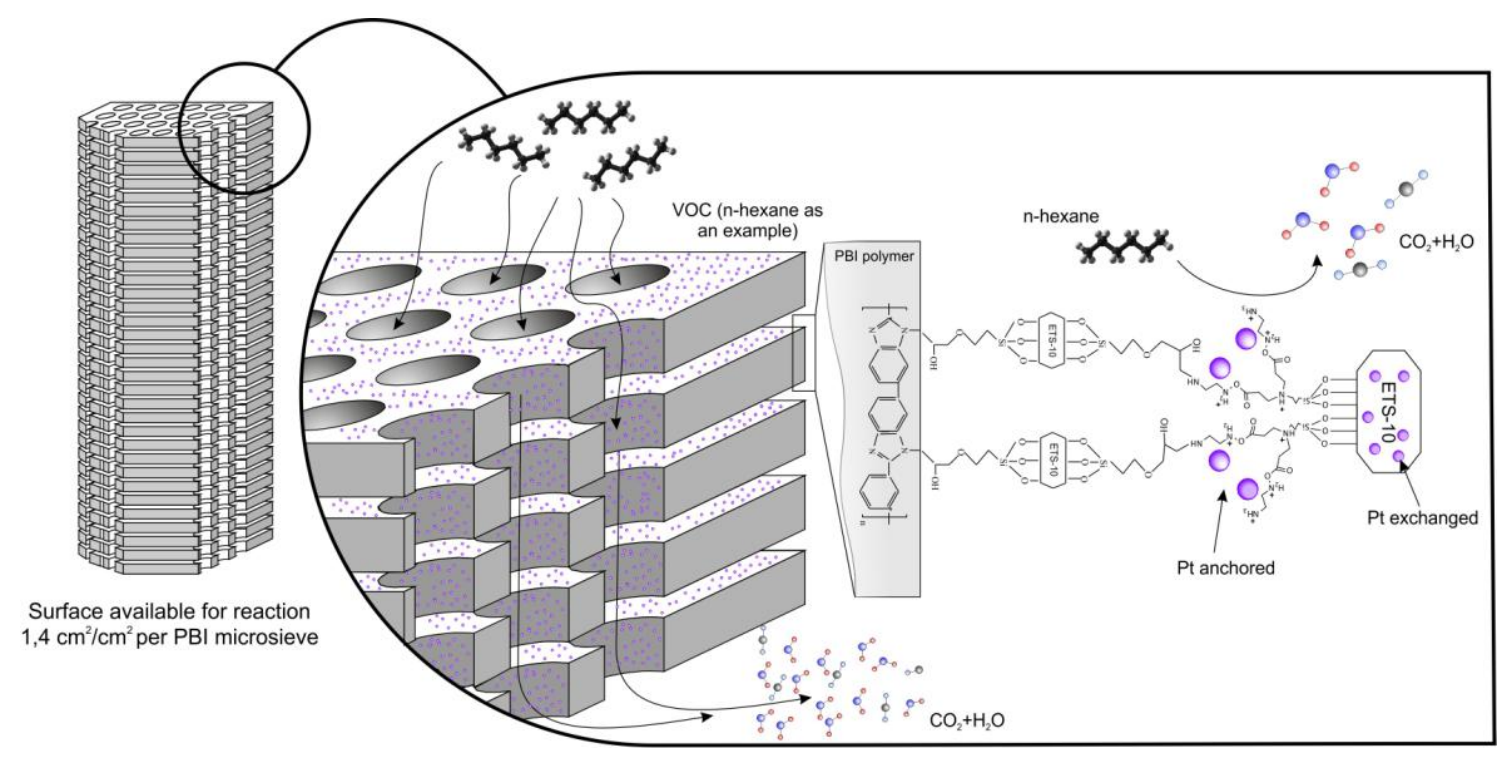

Figure 9. Working principle for catalytic PBI micromonolith-type stack for indoor quality control.
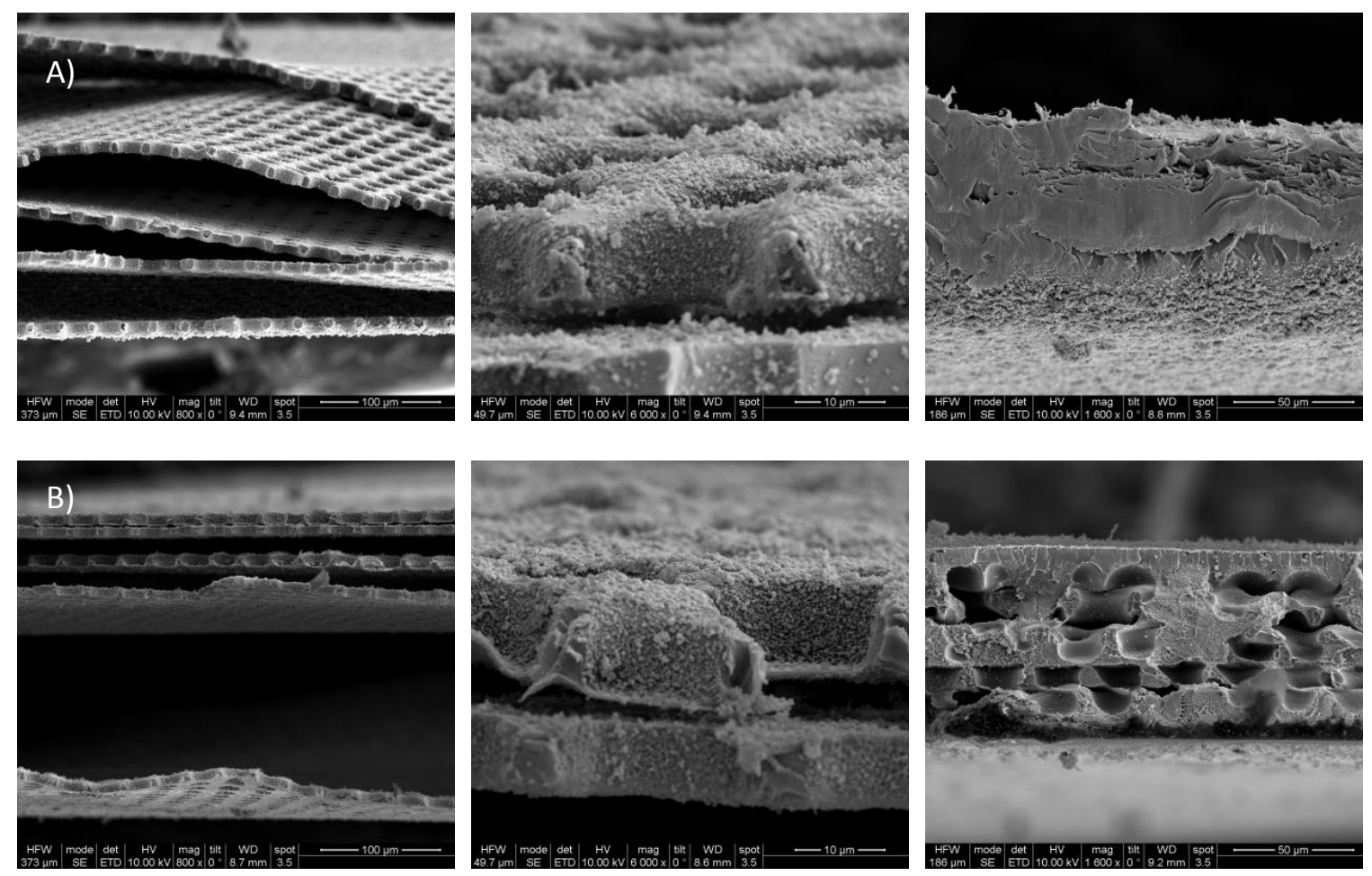

Figure 10. SEM analysis of PBI micromonolith-type stack coated with ETS-10/Pt catalysts: A)

before, and B) after catalytic tests: left) cross section view of the inner part of the assembly

comprising 5 PBI microsieves, centre) detail of the catalyst coverage degree, right) cross

section view of the outer part of the assembly. 
Similarly to catalytic powders, the activated PBI micromonolith-type stack is used in the combustion of $\mathrm{n}$-hexane at low (200 ppm) concentration levels. The contact time for the reaction tests is kept constant at $5 \mathrm{~ms}$. It is worthwhile to underline that this value corresponds to gas hourly space velocity value $\left(84 \mathrm{~h}^{-1}\right)$ rather similar than the used for the catalyst screening in fixed bed reactor $\left(93 \mathrm{~h}^{-1}\right)$. SEM observations of the used micromonoliths (see Figure 10.B) corroborate the chemical and thermal stability of the as prepared flexible microstructured reactors. The reaction results are expressed in Figure 11 as outlet VOC concentration as a function of inlet temperature. As it can be observed, the temperature required to reduce hexane concentration below its threshold limit value (TLV-TWA=50 ppmV) is $225^{\circ} \mathrm{C}$. The $\mathrm{T}_{50}$ is $210^{\circ} \mathrm{C}$, almost $70^{\circ} \mathrm{C}$ higher than the exhibited by ETS-10/Pt in powder form but working at a higher contact time, $565 \mathrm{~ms}$. However, it is almost identical to the previously reported [27] for Pt exchanged ZSM-5 zeolite layers hydrothermally grown onto Si micromonoliths with surface to volume ratio above $300000 \mathrm{~m}^{-1}$ (i.e. $215^{\circ} \mathrm{C}$ at $34 \mathrm{~ms}$ as contact time). When NaY/Pt catalysts are anchored onto such Si micromonoliths by LbL techniques [26], the attained $\mathrm{T}_{50}$ is $250^{\circ} \mathrm{C}$ working at $125000 \mathrm{~mL} / \mathrm{h} \cdot \mathrm{g}_{\mathrm{Pt}+\text { support }}$ and $34 \mathrm{~ms}$ as contact time. 


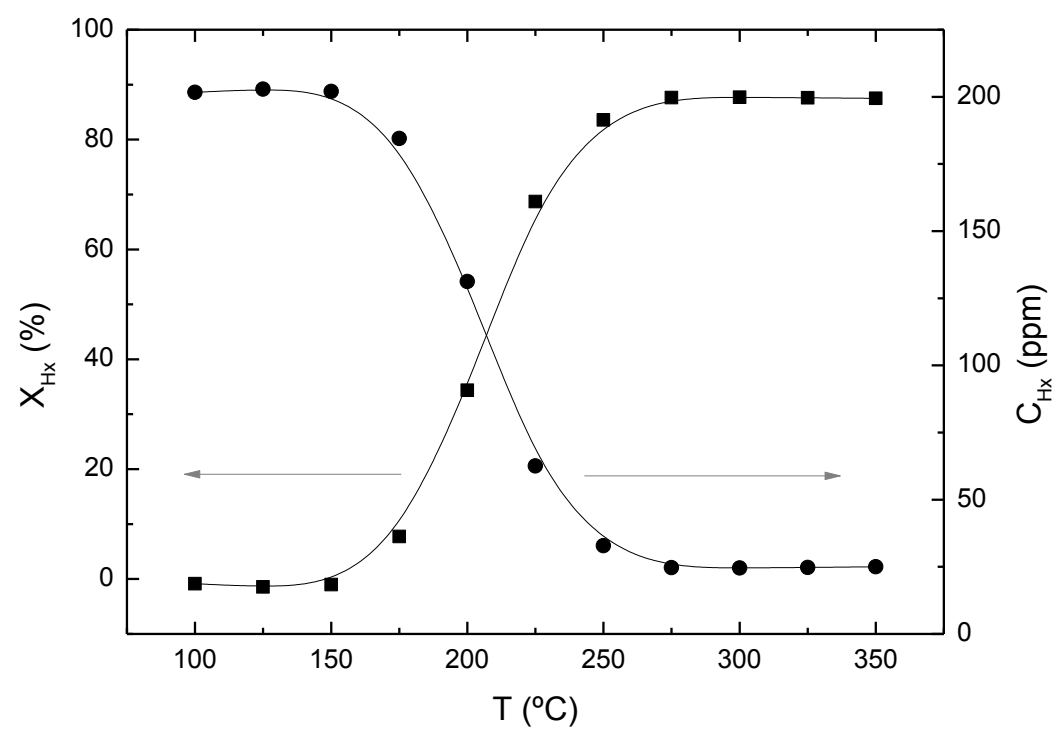

Figure 11. VOC Removal by PBI micromonolith-type stack coated with ETS-10/Pt catalysts as a function of reaction temperature. Reaction conditions: 200 ppmV n-hexane, WHSV $65400 \mathrm{~mL} / \mathrm{h} \cdot \mathrm{g}_{\mathrm{Pt}+\text { support, }}$ contact time $5 \mathrm{~ms}$.

\section{Conclusions}

The preparation of activated PBI micromonolith-type stack with $70000 \mathrm{~m}^{-1}$ as $\mathrm{S} / \mathrm{V}$ ratio and $20 \mu \mathrm{m}$ as microchannel diameter has been accomplished by a simple, reproducible and low cost process involving microtransfer molding, welding and covalent linkage of ETS-10/Pt crystals submicrometric in size. Catalyst loadings up to $5 \mathrm{mg}$ per $\mathrm{cm}^{2}$ exposed surface area are easily obtained thanks to the benzimidazole reactivity and the amino groups grafted on the microporous support. The performance of the as prepared catalytic flexible micromonolith, capable to withstand temperatures up to $350^{\circ} \mathrm{C}$, has been demonstrated in the n-hexane abatement for indoor quality control. The exhibited light-off temperatures are comparable to those previously reported for Si micronoliths with superior high S/V ratio even at shorter contact times due to the due to the full catalyst access. 


\section{Acknowledgements}

The authors would like to acknowledge financial support from the European Commission through the FP7 funded project ZEOCELL (http://ina.unizar.es/zeocell) Grant Agreement 209481; NanoAracat and MICINN through NGG-192 GICSERV programme.

\section{References}

1. R.F. Savinell, M.H. Litt. 1996. Proton Conducting Polymers. US Patent 5,525,436.

2. Q. Li, J.O. Jensen, R.F. Savinell, N.J. Bjerrum. "High temperature proton exchange membranes based on polybenzimidazoles for fuel cells". Prog. Polym. Sci. 34 (2009) 449-477.

3. J.A. Asensio, E.M. Sanchez, P. Gomez-Romero. "Proton-conducting membranes based on benzimidazole polymers for high-temperature PEM fuel cells. A chemical quest". Chemical Society Reviews 39 (8) (2010) 3210-3239.

4. N-H. Li, J.M.J. Frechet. "Polybenzimidazole-supported Heterogeneous Palladium Catalysts". J. Chem. Soc., Chem. Communication 115 (1985) 1100-1101.

5. D.C. Sherrington. "Polymer-supported metal complex alkene epoxidation catalysts". Catalysis Today 57 (2000) 87-104

6. I. U. Castro, D. C. Sherrington, A. Fortuny, A. Fabregat, F. Stüber, J. Font, C. Bengoa. "Synthesis of polymer-supported copper complexes and their evaluation in catalytic phenol oxidation". Catalysis Today 157 (2010) 66-70.

7. R. S. Walmsley, P. Hlangothi, C. Litwinski, T. Nyokong, N. Torto, Z. R. Tshentu." Catalytic Oxidation of Thioanisole Using Oxovanadium(IV)-Functionalized Electrospun Polybenzimidazole Nanofibers". Journal of Applied Polymer Science (2013) 4719-4725.

8. D. Wu, F. Xu, B. Sun, R. Fu, H. He, K. Matyjaszewski. "Design and Preparation of Porous Polymers". Chemical Reviews 112 (2012)3959-4015. 
9. J. Weber, M. Antonietti, A. Thomas. "Mesoporous Poly(benzimidazole) Networks Via Solvent Mediated Templating of Hard Spheres". Macromolecules 40 (2007) 1299-1304.

10. A. Eguizabal, J.Lemus, V. Roda, M. Urbiztondo, F. Barreras, M.P. Pina. “Nanostructured electrolyte membranes based on zeotypes, protic ionic liquids and porous $\mathrm{PBI}$ membranes: Preparation, characterization and MEA testing". International Journal of Hydrogen Energy. International Journal of Hydrogen Energy 37(8) (2012) 7221-7234.

11. E. van de Ven, A. Chairuna, G. Merleb, S.Pacheco Benito, Z. Borneman, K. Nijmeijer. "Ionic liquid doped polybenzimidazole membranes for high temperature Proton Exchange Membrane fuel cell applications". Journal of Power Sources 222 (2013) 202-209.

12. X-J. Zhang, N. Bian, L-J Mao, Q. Chen, L. Fang, A-D. Qi and B-H. Han. "Porous Polybenzimidazoles via Template-Free Suzuki Coupling Polymerization: Preparation, Porosity, and Heterogeneous Catalytic Activity in Knoevenagel Condensation Reactions". Macromolecular Chemistry and Physics 213 (5)(2012) 1575-1581.

13. D. Mecerreyes, H. Grande, O. Miguel, E. Ochoteco, R. Marcilla, I. Cantero. "Porous polybenzimidazole membranes doped with phosphoric acid: Highly proton-conducting solid electrolytes". Chem. Mater. 16 (2004) 604-607.

14. A. Eguizabal, J.Lemus, O. Garrido, M.Urbiztondo, J. Soler, A. Blazquez, M.P. Pina. “Novel Hybrid Membranes based on Polybenzimidazole and ETS-10 titanosilicate type material for High Temperature PEMFCs: a comprehensive study on dense and porous systems". Journal of Power Sources 196 (21) (2011) 8994-9007.

15. C-H. Shen, L-C. Jheng, S. L-C. Hsu, J. T-W. Wang. "Phosphoric acid-doped cross-linked porous polybenzimidazole membranes for proton exchange membrane fuel cells". Journal of Materials Chemistry 21 (39) (2011) 15660-15665.

16. B.D. Gates, Q. Xu, M. Stewart, D. Ryan, C.G. Willson, G.M. Whitesides. "New Approaches to Nanofabrication: Molding, Printing, and Other Techniques". Chem. Rev. 105 (2005) 1171-1196. 
17. L. Vogelaar, R.G.H. Lammertink, J. N. Barsema, W. Nijdam, L.A.M. Bolhuis-Versteeg, C. J. M. van Rijn, M. Wessling. "Phase Separation Micromolding: A New Generic Approach for Microstructuring Various Materials". Small 1(6) (2005) 645 -655.

18. M. Girones, I.J. Akbarsyah, W. Nijdam, C.J.M. van Rijn, H.V. Jansen, R.G.H. Lammertink, M. Wessling. "Polymeric microsieves produced by phase separation micromolding". Journal of Membrane Science 283 (2006) 411-424.

19. J. Jong, B. Ankoné, R.G.H. Lammertink, M. Wessling. New replication technique for the fabrication of thin polymeric microfluidic devices with tunable porosity. Lab on Chip 5 (2005) $1240-1247$.

20. M. Bikel, I.G.M. Pünt, R.G.H. Lammertink, M. Wessling. “Micropatterned Polymer Films by Vapor-Induced Phase Separation Using Permeable Molds". Applied Materials \& Interfaces $1(12)(2009)$ 2856-2861.

21. A. Eguizabal, M. Urbiztondo, M.P. Pina. "Fast route to prepare microstructured benzimidazole platforms for high temperature applications". Submitted to Journal of Membrane Science.

22. N. Navascués, M. Escuin, Y. Rodas, S. Irusta, R. Mallada, J. Santamaria. "Combustion of Volatile Organic Compounds at Trace Concentration Levels in Zeolite-Coated Microreactors" Ind. Eng. Chem. Res. 49 (2010) 6941-6947.

23. M.A. Urbiztondo, E. Valera, T. Trifonov, R. Alcubilla, S. Irusta, M.P. Pina, A. Rodríguez, J. Santamaría. "Development of microstructured zeolite films as highly accessible catalytic coatings for microreactors". Journal of Catalysis 250 (1) (2007) 190-194.

24. M.P. Pina, R. Mallada, M. Arruebo, M. Urbiztondo, N. Navascués, O. de la Iglesia, J. Santamaria. "Zeolite films and membranes. Emerging applications" Microporous and Mesoporous Materials 144 (2011) 19-27. 
25. I. Pellejero, M. Urbiztondo, M.P. Pina, J. Santamaria. "Reinforced SIL-1 micromembranes integrated on chip. Application to $\mathrm{CO}_{2}$ separation" Journal of Membrane Science. 10.1016/j.memsci.2014.02.007.

26. S. Nuñez, D. Vega, M. Urbiztondo, R. Mallada, M.P. Pina, A. Rodriguez, J. Santamaría. "Pt exchanged NaY type zeolite coatings on 3D Macroporous Si Structures for VOC removal". Book of Abstracts IMRET12, $12^{\text {th }}$ International conference on Micro-Reaction Technology. February 2012, Lyon (France).

27. I. Marin, E. Adrover, D. Vega, M. Urbiztondo, M.P. Pina, R. Mallada, J. Santamaría. "Fast microwave synthesis of Pt-MFI zeolite coatings on silicon micromonoliths: application to VOC catalytic combustion". Green Processing \& Synthesis 2 (2012)169.

28. T. Huang, W. Tu. "Modification of functionalized mesoporous silica on the formation and the catalytic performance of platinum nanocatalysts". Applied Surface Science 255(17) (2009) 7672-7678.

29. D. Sebastian, J. C. Calderon, J. A. Gonzalez-Exposito, E. Pastor, M. V. Martinez-Huerta, I. Suelves, R. Moliner and M. J. Lazaro. "Influence of carbon nanofibers properties as electrocatalyst support on the electrochemical performance for PEM fuel cells". International Journal of Hydrogen Energy, 2010, 35, 9934-9942.

30. N. Karbass, V.Sans, E. Garcia-Verdugo,M.I. Burguete, SV. Luis. "Pd(0) supported onto monolithic polymers containing IL-like moieties. Continuous flow catalysis for the Heck reaction in near-critical EtOH". Chemical Communication (2006) 3095-3097.

31. V. Sebastian, S. Irusta, R. Mallada, J. Santamaria. "Selective oxidation of CO in the presence of $\mathrm{H}_{2}, \mathrm{CO}_{2}$ and $\mathrm{H}_{2} \mathrm{O}$, on different zeolite-supported Pt catalysts". Applied Catalysis A: General 366(2) (2009) 242-251. 


\section{Table List}

Table 1. Main Properties of the Pt based catalyts used in this work.

Table 2. Catalytic properties for some of the as catalysts prepared in this work.

\section{Figure Captions}

Figure 1. Schematic overview of the preparation routes for the Pt based catalysts studied in this work.

Figure 2.A) General Scheme for the Pt based catalysts anchoring on the PBI surface by means of epoxi functionalized microporous connectors. B) General Scheme for the Pt based catalysts anchoring on the as prepared PBI by means of benzimidazole ligand.

Figure 3.A) ATR-FTIR analyses, and B) TGA for $\mathrm{Na} / \mathrm{K}$ ETS-10 crystals before and after amino grafting with Acrylate

Figure 4. TEM analyses for the catalytic powders based on NaY.

Figure 5. TEM analyses for the catalytic powders based on ETS-10.

Figure 6. XRD analysis for ETS-10/Pt catalyst.

Figure 7. Light-off curves of Pt based catalysts supported on: A) NaY, and B) ETS-10 materials. Reaction conditions: $200 \mathrm{ppmV}$ n-hexane, WHSV $72000 \mathrm{~mL} / \mathrm{h} \cdot \mathrm{g}$ Pt+support, contact time $565 \mathrm{~ms}$.

Figure 8. ATR-FTIR analyses of epoxi functionalized: A) NaY, and B) ETS-10 type supports.

Figure 9. Working principle for catalytic PBI micromonolith-type stack for indoor quality control.

Figure 10. SEM analysis of PBI micromonolith-type stack coated with ETS-10/Pt catalysts: A) before, and B) after catalytic tests: left) cross section view of the inner part of the assembly comprising $5 \mathrm{PBI}$ microsieves, centre) detail of the catalyst coverage degree, right) cross section view of the outer part of the assembly. 
Figure 11. VOC Removal by PBI micromonolith-type stack coated with ETS-10/Pt catalysts as a function of reaction temperature. Reaction conditions: $200 \mathrm{ppmV}$ n-hexane, WHSV $65400 \mathrm{~mL} / \mathrm{h} \cdot \mathrm{g}_{\text {Pt+support, }}$ contact time $5 \mathrm{~ms}$. 


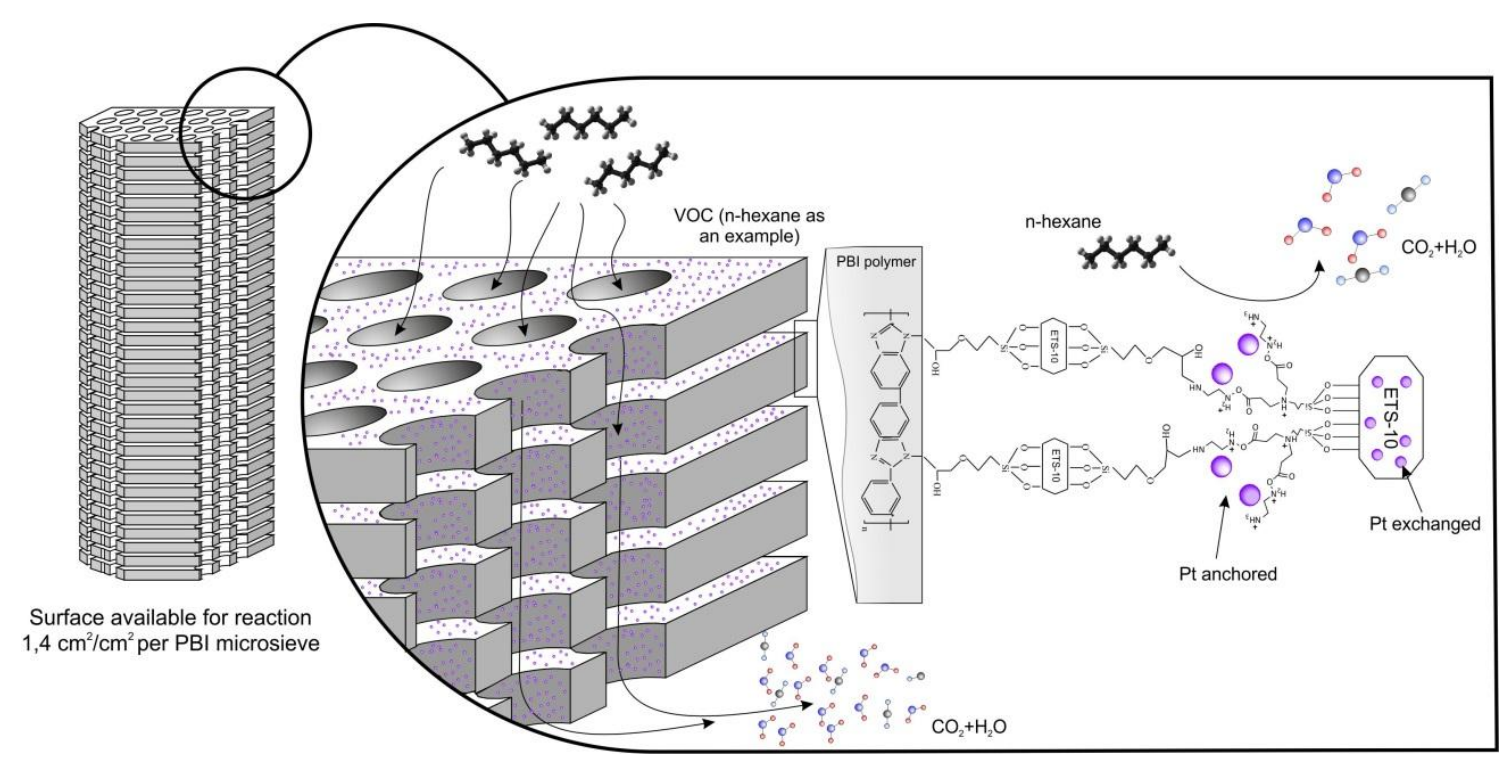




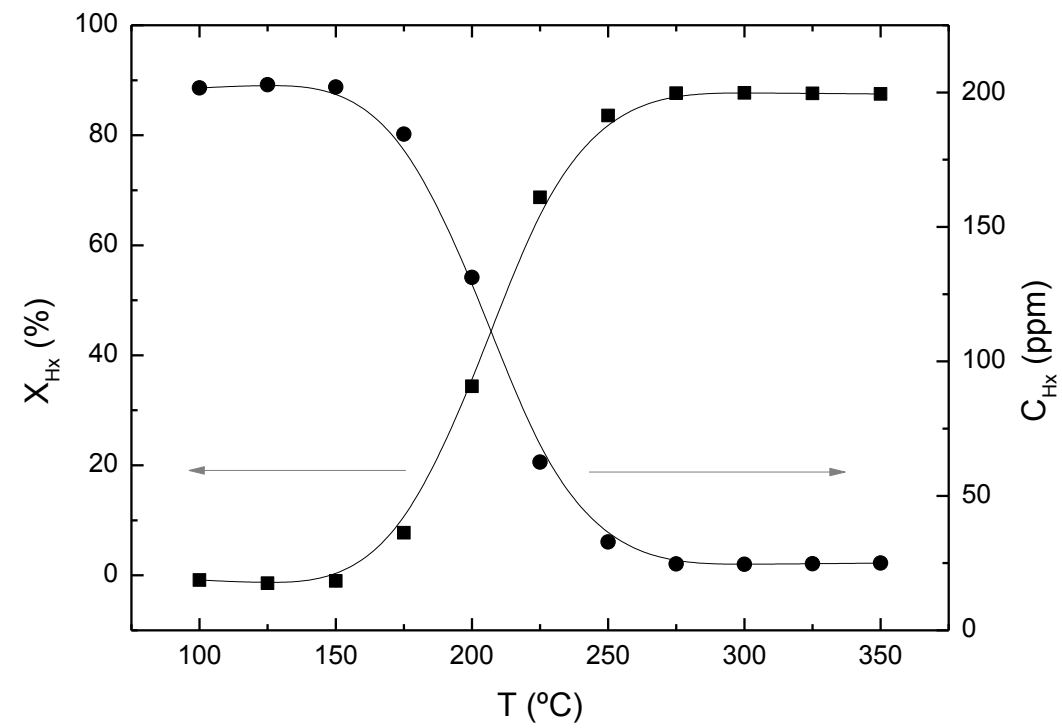




\section{Highlights}

- Flexible Micromonoliths $70000 \mathrm{~m}^{-1}$ as S/V ratio and $20 \mu \mathrm{m}$ as characteristic length

- PBI micromonolith-type stack as microstructured support

- Pt nanoparticles supported on amino functionalized ETS10 crystals

- Pt based catalytic films on PBI microchannels for $n$-hexane combustion

- $75 \%$ hexane conversion at 225ㄷ $\mathrm{C}$ with $5 \mathrm{~ms}$ as gas-solid contact time 


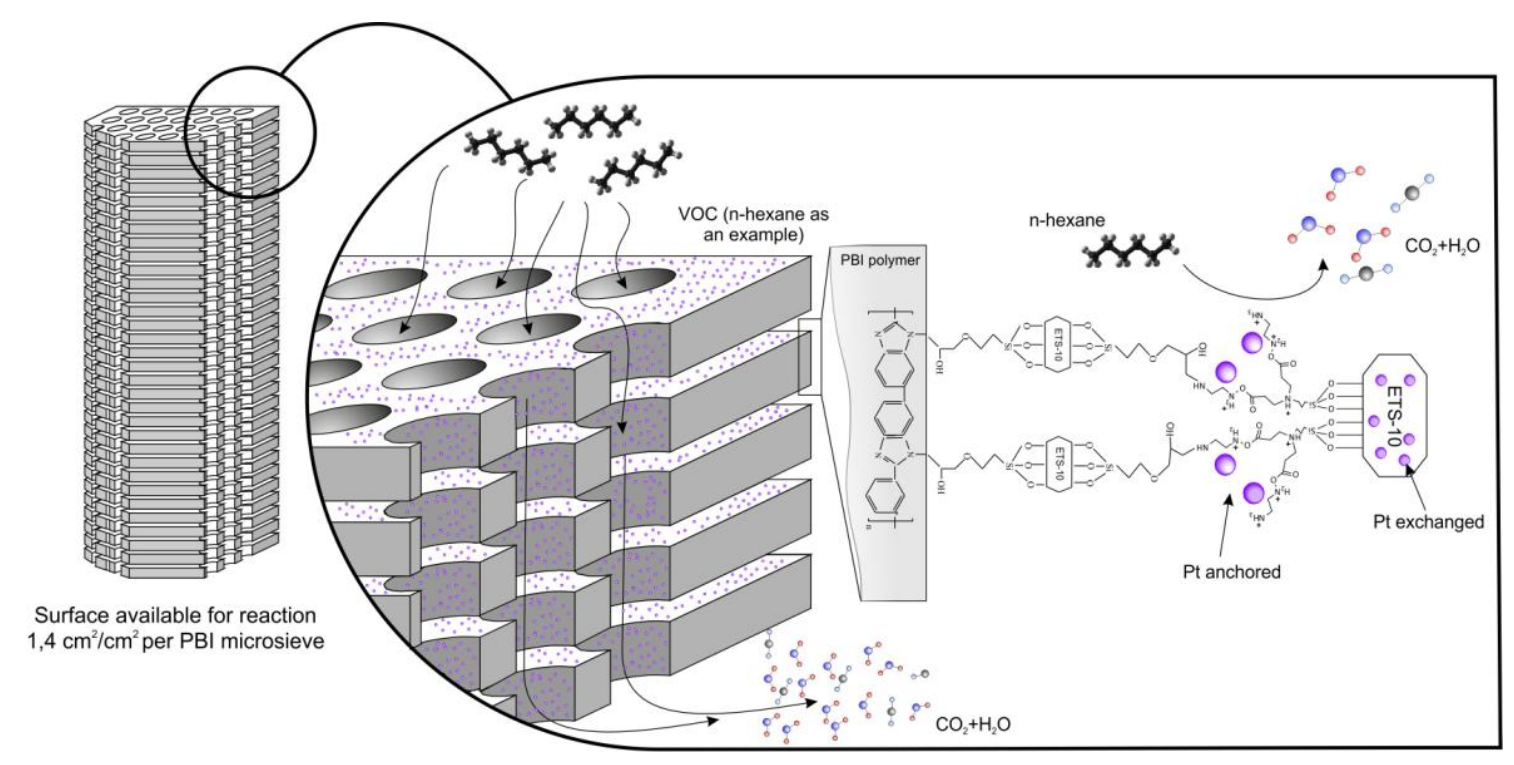

